\title{
Evaluation of PCR Assay over Culture for the Detection of Acanthamoeba Spp. In Amoebic Keratitis and Amoebic Meningitis/ Meningoencephalitis Patients in India
}

\author{
Himanshu SB${ }^{1}$, Gita $S^{2}$, Anita Panda ${ }^{3}$, Pooja $B^{3}$ and Manjari T4 \\ ${ }^{1}$ Department of Ocular Microbiology, Dr. R. P. Centre for Ophthalmic Sciences, All India \\ Institute of Medical Sciences, India \\ ${ }^{2}$ Department of Ocular Microbiology, Dr. R. P. Centre for Ophthalmic Sciences and prof. \&
} Head dept. of Microbiology, All India Institute of Medical Sciences, India

${ }^{3}$ Department of Opthalmology, Dr. R. P. Centre for Ophthalmic Sciences, All India Institute of Medical Sciences, India ${ }^{4}$ Professor Neurology, Neurosciences Centre, All India Institute of Medical Sciences, India

*Corresponding author: Himansu Sekhar Behera, Department of Ocular Microbiology, Dr. R. P. Centre for Ophthalmic Sciences, All India Institute of Medical Sciences, New Delhi, India, Tel: 01126593171; Email: himansubt@gmail.com

\section{Abstract}

Aims: Evaluation of PCR assay over culture for the detection of Acanthamoeba spp. in corneal scrapings of suspected amoebic keratitis patients and CSF from suspected amoebic meningitis/ meningoencephalitis patients.

Methods and Results: Corneal scrapings and CSF were collected from 183 and 149 patients suspected of having amoebic Keratitis and Acanthamoeba meningitis/ meningoencephalitis (AME) respectively from 2010 to 2015. A part of the specimen (corneal scraping and CSF) was inoculated onto a 2\% non-nutrient agar plate overlaid with E. coli. for culture and a second part of the specimen was placed in 500 $\mu$ l PBS buffer (pH 7.4) for molecular diagnosis. Acanthamoeba spp. could be detected in culture from 29(15.84\%) cases, by PCR assay from 32(17.48\%) cases in suspected amoebic keratitis patients. Likewise out of 149 suspected patients of Acanthamoeba meningitis/ meningoencephalitis 10(06.71\%) cases were positive in culture where as 11(07.38\%) were positives by PCR assay.

Conclusion: PCR assay was found to be more sensitive and specific than culture for detection of Acanthamoeba spp. in corneal scrapings of suspected amoebic Keratitis patients and CSF collected from suspected AME patients.

Significance and Impact of Study: PCR assay should be performed along with culture (gold standard) for efficient laboratory diagnosis of Acanthamoeba spp. in patient samples. 
Keywords: Acanthamoeba keratitis; Acanthamoeba meningitis/ meningoencephalitis; 18S rDNA PCR; PCR assay of Acanthamoeba spp

Abbreviations: AK: Acanthamoeba keratitis; SLE: Systemic lupus erythematosis; ASA.S1: Acanthamoeba specific amplimer.

\section{Introduction}

Acanthamoeba keratitis (AK) is an acute; sight threatening infection of cornea, if untreated can lead to permanent blindness [1]. Previously Acanthamoeba keratitis was considered to be a rare entity but in recent years due to development of advanced diagnostic procedures the magnitude of Acanthamoeba keratitis has increased rapidly across the world [2-5]. In developed countries most of the reported cases were seen to be associated with the use of soft contact lens where as in developing countries like India most reported cases were seen to be associated with non-contact lens wearers rather than the contact lens wearers [4-6].

Acanthamoeba meningitis/meningoencephalitis is a rare and insidious, chronic infection of the central nervous system in persons with compromised metabolic, physiologic, or immunologic functions due to either AIDS or diabetes or Systemic lupus erythematosis (SLE) or undergone organ transplantation or in patients receiving chemotherapy/ radiotherapy etc [7-9]. Apart from all these cases there have been a few reported cases of Acanthamoeba meningitis/meningoencephalitis infections in healthy individuals with no known previous immunodeficiency $[10,11]$.

An early diagnosis of Acanthamoeba keratitis and Acanthamoeba meningitis/meningoencephalitis infections increases the prognosis. For laboratory diagnosis, culture on $2 \%$ non-nutrient agar plate overlaid with E.coli. and molecular diagnosis using PCR assay are usually used worldwide. Sometimes some positive cases of these two infections are misdiagnosed due to use of only culture (gold standard) for routine laboratory diagnosis. PCR assay for amplification of "Acanthamoeba specific amplimer (ASA.S1)", a 464bp region within the 18S rRNA gene was found suitable for routine molecular diagnosis [12]. A major advantage of choosing this region for PCR assay is that, it detects all known Acanthamoeba subgroups [12]. The present study was aimed to evaluate the usefulness of PCR assay over culture in a clinical setting with a large number of amoebic keratitis and amoebic meningitis/ meningoencephalitis patients for the detection of Acanthamoeba spp.

\section{Materials and Methods}

\section{Patient Selection and Collection of Clinical Specimens}

Corneal scrapings were collected by the ophthalmologists from 183 patients clinically suspected of having Acanthamoeba Keratitis with symptoms of unilateral red eye, foreign body sensation, blurred vision, severe unbearable pain, ring shaped stromal infiltrates and photophobia reporting to the Outpatient department/ casualty services of $\mathrm{Dr} \mathrm{R}$. P. Centre for Ophthalmic Sciences, New delhi from 2010 to 2015. Likewise CSF was collected by the neurologists from 149 patients clinically suspected of having Acanthamoeba meningitis/ meningoencephalitis with symptoms of seizures, aphasia, ataxia, altered mental state and lethargy reporting to the Outpatient department/ casualty services of Neurosciences centre, All India Institute of Medical Sciences, New Delhi, India from 2010 to 2015. A part of the collected specimen (corneal scraping or CSF) was inoculated onto a $2 \%$ non-nutrient agar plate overlaid with E. coli., for culture and a second part of the specimen(corneal scraping) was placed in $500 \mu \mathrm{l}$ PBS buffer ( $\mathrm{pH}$ 7.4) for PCR assay. CSF was directly taken for molecular diagnosis by PCR assay.

\section{Isolation of Acanthamoeba spp. in culture}

Inoculated $2 \%$ non-nutrient agar plates were sealed and incubated at $30^{\circ} \mathrm{C}$ for 14 days. Plates were examined regularly post incubation and observed under a light microscope (10X \& 40X objectives) (Nikon, Japan) for the appearance of growth of Acanthamoeba spp. over agar surface.

\section{PCR Assay}

DNA was isolated from corneal scrapings (collected in $500 \mu \mathrm{l}$ PBS buffer) and CSF using QIAmp DNA Mini Kit (QIAgen), following the manufacturer's instructions, and used for PCR assays. PCR assay for amplification of the genus specific Acanthamoeba specific amplimer (ASA.S1) region of $18 \mathrm{~S}$ rRNA gene ( $\sim 464 \mathrm{bp}$ ) was performed with 
the forward primer JDP1 GGCCCAGATCGTTTACCGTGAA-3') and reverse primer JDP2 (5'-TCTCACAAGCTGCTAGGGGAGTCA-3')[12]. PCR reaction mix of $20 \mu \mathrm{l}$ was prepared with $1 \mathrm{X}$ reaction buffer(Fermentas), $\quad 2.5 \mathrm{mM} \quad \mathrm{MgCl}_{2}, \quad 200 \mu \mathrm{M}$ dNTPs (Fermentas), $0.4 \mu \mathrm{M}$ forward and reverse primers (IDT), 1.25U Taq Polymerase (Fermentas) and milliQ water q.s. $5 \mu \mathrm{l}$ of extracted DNA ( $\sim 0.5 \mathrm{ng})$ was added to the reaction mixture and processed for PCR assay. PCR assay was performed in a thermal cycler (Applied Bio system, USA) with the temperature profile of initial denaturation at $94^{\circ} \mathrm{C}$ for 5 mins, followed by denaturation at $94^{\circ} \mathrm{C}$ for $1 \mathrm{~min}$, primer annealing at $61^{\circ} \mathrm{C}$ for $1 \mathrm{~min}$, strand elongation at $72^{\circ} \mathrm{C}$ for $1 \mathrm{~min}$ for 35 cycles, with the final elongation at $72^{\circ} \mathrm{C}$ for 10 mins. Reaction mixture with $5 \mu \mathrm{l}$ distilled water was used as a negative control and reaction mixture with DNA isolated from known isolates of Acanthamoeba spp. was used as a positive control in PCR assay. Amplified PCR products were electrophoresed on $1.5 \%$ agarose gel and was visualised under a Gel documentation system (Syngene).

\section{Statistical Analysis}

Diagnostic data (culture and PCR assay) obtained from 183 patients clinically suspected of having Acanthamoeba keratitis and 149 patients clinically suspected of having Acanthamoeba meningitis/ meningoencephalitis were used for determining sensitivity, specificity, positive predictive values (PPV), and negative predictive values (NPV) of PCR assay using culture results as the "gold standard". Formulas used for calculation are as follows: sensitivity $=$ (number of true positives/total number of true positives + total number of false negative) X 100, specificity $=$ (number of true negatives $/ /$ total number of true negative + total number of false positives) X 100, PPV $=$ (total number of true positives $/$ total number of true positives + total number of false positives) X 100, NPV = (Total number of true negatives/total number of true negatives + total number of false negatives) X 100 .

\section{Results}

Age \& sex profile of 183 patients clinically suspected of having Acanthamoeba keratitis and 149 patients clinically suspected of having Acanthamoeba meningitis/ meningoencephalitis included in this study are given in
(Tables 1 \& 2) respectively. Of the 183 suspected Acanthamoeba keratitis patients 109 were male and 74 were female. Likewise of the 149 suspected Acanthamoeba meningitis/ meningoencephalitis patients 100 were male and 49 were female.

\begin{tabular}{|c|c|}
\hline Age Group of Patients (Yrs) & No. of Samples \\
\hline $0-10$ & 6 \\
\hline $11-20$ & 26 \\
\hline $21-30$ & 43 \\
\hline $31-40$ & 33 \\
\hline $41-50$ & 30 \\
\hline $51-60$ & 26 \\
\hline $61-70$ & 13 \\
\hline $71-80$ & 05 \\
\hline $81-90$ & 01 \\
\hline
\end{tabular}

Table 1: Age distribution of 183 patients with suspected Acanthomoeba keratitis.

\begin{tabular}{|c|c|}
\hline Age Group of Patients (Yrs) & No. of Samples \\
\hline $0-10$ & 49 \\
\hline $20-\mathrm{Nov}$ & 40 \\
\hline $21-30$ & 19 \\
\hline $31-40$ & 14 \\
\hline $41-50$ & 10 \\
\hline $51-60$ & 8 \\
\hline $61-70$ & 5 \\
\hline $71-80$ & 3 \\
\hline $81-90$ & 1 \\
\hline
\end{tabular}

Table 2: Age distribution of 149 patients with suspected Acanthamoeba meningitis/ meningoencephalitis.

Acanthamoeba spp. were visible in the culture on $2 \%$ non nutrient agar plate overlaid with E.coli. using an inverted microscope (Nikon) after 4 days and covered the entire agar surface after 7 days (Figure 1A). Nucleotide sequences for ASA.S1 region of 18s rRNA gene produced clear band of $\sim 460 \mathrm{bp}$ length when electrophoresed in $1.5 \%$ agarose gel for all positive specimens (Figure 1B). 

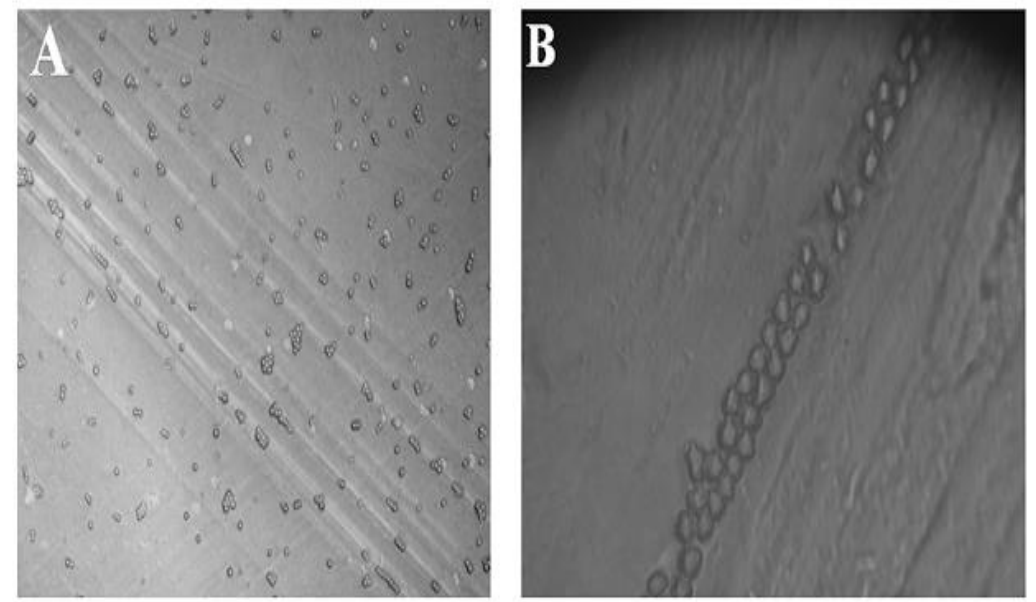

Figure 1: Positive culture of the Acanthamoeba spp. as visualized by inverted microscopy (A) with 10X objective (B) with 40X objective.

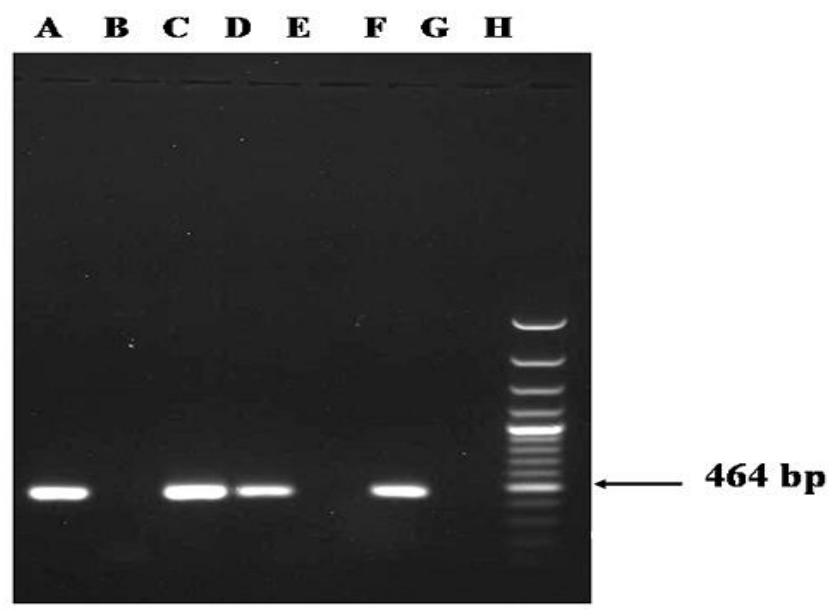

Figure 2: PCR amplified product of $\sim 460$ bp length of ASA.S1 region of $18 \mathrm{~S}$ rRNA gene of Acanthamoeba spp. obtained from corneal scrapings of suspected amoebic keratitis patients.

$\{\mathrm{A}=$ Positive Control ; $\mathrm{B}=$ Negative Control (Distilled water); $\mathrm{C}=$ Positive isolate; $\mathrm{D}=$ Positive isolate; $\mathrm{E}=$ Negative isolate; $\mathrm{F}=$ Positive isolate; $\mathrm{G}=$ Negative isolate; $\mathrm{H}=\mathrm{DNA}$ ladder $(100 \mathrm{bps})\}$

Of the 183 patients clinically suspected of having Acanthamoeba keratitis, $29(15.84 \%)$ were found to be culture positive for Acanthamoeba spp., 32(17.48\%) were positive in PCR assay, and 28(15.30\%) were positive by both culture \& PCR assays $(\mathrm{P}<0.0001, \mathrm{P}$-give $95 \%$ confidence interval) (Table 3). Likewise out of 149 patients clinically suspected of having Acanthamoeba meningitis/ meningoencephalitis $10(06.71 \%)$ were found positive by culture, 11(07.38\%) were positive by PCR assay and $10(06.71 \%)$ were positive by both culture and 
PCR assay $(\mathrm{P}<0.0001, \mathrm{P}$-give $95 \%$ confidence interval) (Table 4). P-vale was calculated with two tailed Fisher's exact test.

\begin{tabular}{|c|c|c|}
\hline Culture & \multicolumn{2}{|c|}{ PCR Assay } \\
\hline (Gold stand.) & (Positive) & (Negative) \\
\hline \multirow{2}{*}{ Positive } & 28 & 1 \\
\cline { 2 - 3 } & $-15.30 \%$ & $-0.54 \%$ \\
\hline \multirow{2}{*}{ Negative } & 4 & 150 \\
\cline { 2 - 3 } & $-2.10 \%$ & $-81.96 \%$ \\
\hline
\end{tabular}

Table 3: $2 X 2$ table of culture and PCR results for 183 suspected patients of having amoebic keratitis.

\begin{tabular}{|c|c|c|}
\hline Culture & \multicolumn{2}{|c|}{ PCR Assay } \\
\hline (Gold stand.) & (Positive) & (Negative) \\
\hline \multirow{2}{*}{ Positive } & 10 & 0 \\
\cline { 2 - 3 } & $-6.71 \%$ & $0.00 \%$ \\
\hline \multirow{2}{*}{ Negative } & 1 & 138 \\
\cline { 2 - 3 } & $-0.67 \%$ & $-92.61 \%$ \\
\hline
\end{tabular}

Table 4: 2X2 table of culture and PCR results for 149 suspected patients of having Acanthamoeba meningitis/ meningoencephalitis.

Sensitivity and specificity of PCR assay in case of suspected amoebic keratitis patients were found to be $96.55 \%$ and $97.40 \%$ respectively with culture as the gold standard. Similarly sensitivity and specificity of PCR assay in case Acanthamoeba meningitis/ meningoencephalitis patients were found to be $100.00 \%$ and $99.28 \%$ respectively with culture as the gold standard. Positive predictive value (PPV) and Negative predictive value (NPV) of PCR assay in case of amoebic keratitis was found to be $87.50 \%$ and $100 \%$ respectively and in case of Acanthamoeba meningitis/ meningoencephalitis it was found to be $90.90 \%$ and $100 \%$ respectively.

\section{Discussion}

Acanthamoeba spp. are mostly detected from clinical specimens by three laboratory diagnostic methods such as direct examination by several staining procedures, culture and PCR assay [13,14]. Among all these three methods, staining and PCR assay can provide a rapid detection of Acanthamoeba spp. as compared to culture $[15,13]$. In a pilot study it was reported that, Acanthamoeba spp. was misdiagnosed in $60-70 \%$ of direct examination by staining, hence this method cannot be only implemented for accurate laboratory diagnosis [13]. However culture on $2 \%$ non-nutrient agar plate overlaid with E.coli is the easiest and most widely used method for laboratory diagnosis of Acanthamoeba spp. which is also considered as the gold standard worldwide [16]. This is probably due to its low cost, easy to handle and can be carried out by a person without much more technical knowledge in molecular biology. There is still a drawback with culture which takes a longer incubation time (7-14 days) for reporting the results and there may some false positive cases in case of contact lens due to contamination as reported from some previous studies $[16,13]$. With the introduction of PCR assay into laboratory diagnosis it was widely accepted along with culture and staining. The drawbacks of culture and staining were overcome by PCR assay in terms of sensitivity, specificity, rapidity and accuracy.

Several regions of nuclear DNA and ribosomal DNA were chosen for molecular diagnosis by PCR assay, among which 18S rRNA gene-based PCR assay is widely used for its high sensitivity and specificity. Vodkin et al. were the first to use PCR assay for the detection of several strains Acanthamoeba spp. in clinical specimens, using primer pairs ACARNA for1383 and ACARNA.rev1655 that amplifies a $272 \mathrm{bp}$ region of $18 \mathrm{~s}$ rDNA [17]. These pair of primers were successful in distinguishing Acanthamoeba from Naegleria. Later Lehmann, et al. also tested with another set of primers P1GP for 2379 and P1GP.Rev2632, to amplify a 253 bp region of 18S rDNA gene of Acanthamoeba spp. [16]. Analyzing complete 18S rDNA gene sequences Schroeder, et al. [12] had shown that, the above two primer pairs could also amplify $18 \mathrm{~S}$ rDNA gene sequences of related amoebas i.e., Balamuthia and Hartmanella spp. Hence he designed a new set of genus specific primers i.e. JDP1 and JDP2 which could amplify a $\sim 464$ bp region of 18S rDNA of Acanthamoeba spp. [12]. These pair of primers were genus specific for Acanthamoeba and could not amplify from DNA of closely related amoebae. From that time onwards these set of primers are widely used in laboratory diagnosis of all species of Acanthamoeba all over the world [18,19,4].

In a study it was reported that, Acanthamoeba spp. could be detected by PCR assay in $71.4 \%$ of suspected amoebic keratitis patients whereas culture was positive in only $14.3 \%$ of the isolates [20]. In another pilot study to compare culture vs. PCR it was reported that, out of 80 patients of suspected amoebic keratitis, 4 additional positive cases were obtained by PCR assay than culture [21]. The present study also corroborates with the previous studies, where we found 3 more Acanthamoeba positive cases in amoebic keratitis and 1 more positive 
case in Acanthamoeba meningitis/ meningoencephalitis by PCR assay than culture on $2 \%$ non-nutrient agar plate.

Lehmann, et al. had reported the advantage of PCR assay over culture in terms of sensitivity and specificity [16]. They reported a sensitivity of $84 \%$ and $66 \%$ for the PCR assay in diagnosis of strains of Acanthamoeba spp. from corneal scrapings and tear specimens respectively in comparison to just $53 \%$ by the traditional culture method [16]. In another study it was reported that, PCR assay has a higher sensitivity of $87.5 \%$ for detection of Acanthamoeba spp. from corneal scrapings as against culture which was 70\% [4]. In a pilot study conducted by Niyyati, et al. [20]. It was reported that, sensitivity and specificity of PCR-based method was $71.4 \%$ and $100 \%$ respectively taking culture as the gold standard in 28 suspected Acanthamoeba keratitis patients [20]. The present study corroborates with the previous studies which showed PCR assay is having a higher sensitivity and specificity in detecting Acanthamoeba spp. from corneal scrapings of suspected amoebic keratitis patients and CSF of suspected Acanthamoeba meningitis/ meningoencephalitis patients. Apart from sensitivity and specificity, PCR assay was found to having high PPV and NPV values which further confirms that "PCR assay is a good diagnostic test for detecting Acanthamoeba spp. in clinical specimens". Therefore at present both culture and PCR assay are being widely used for laboratory diagnosis of Acanthamoeba keratitis and Acanthamoeba meningitis/ meningoencephalitis to maximise detection $[4,22,12,18]$.

Summarising the whole study, we evaluated the effectiveness of PCR assay over culture in detecting Acanthamoeba spp. from corneal scrapings of suspected amoebic keratitis patients and CSF from suspected Acanthamoeba meningitis/ meningoencephalitis patients. From our pilot study we suggest that, PCR assay should be used to supplement the conventional culture for the detection of amoebic keratitis and Acanthamoeba meningitis/ meningoencephalitis infections [23].

\section{Conclusions}

PCR assay was found to be more sensitive and specific than culture for detection of Acanthamoeba spp. in corneal scrapings of suspected amoebic Keratitis patients and CSF collected from suspected AME patients. PCR assay should be performed along with culture (gold standard) for efficient laboratory diagnosis of Acanthamoeba spp. in patient samples.

\section{Ethical Approval}

All procedures performed in this study involving human participants were in accordance with the ethical standards of the institute (AIIMS, New Delhi) and ethical clearance was obtained from the institute.

\section{Acknowledgments}

This study was supported by an Adhoc Research grant from Indian Council of Medical Research to Dr. Gita Satpathy.

\section{Conflict of Interests}

The authors declare that there are no conflicts of interest related to this work.

\section{Contributorship}

HB: Performed all laboratory experiments and drafted the manuscript. AP: Clinical team leader did clinical examinations and provided specimens. PB: Did clinical work and provided specimens. MT: Clinical team leader did clinical examinations and provided clinical specimens. GS: Conceived the idea, arranged the funding and supervised the work, shaped the drafted manuscript.

\section{Informed Consent}

Consent was obtained from all individual participants included in the study.

\section{Funding and all other required documents}

There are no funding agencies to report for this submission.

\section{References}

1. Visvesvara GS, Moura H, Schuster FL (2007) Pathogenic and opportunistic free-living amoebae: Acanthamoeba spp., Balamuthia mandrillaris, Naegleria fowleri, and Sappinia diploidea. FEMS Immunol Med Microbiol 50(1): 1-26.

2. Beattie TK, Tomlinson A, McFadyen AK, Seal DV, Grimason AM (2003) Enhanced attachment of acanthamoeba to extended-wear silicone hydrogel contact lenses: a new risk factor for infection?. Ophthalmol 110(4): 765-771. 
3. Patel A, Hammersmith K (2008) Contact lens-related microbial keratitis: recent outbreaks. Curr Opin Ophthalmol 19(4): 302-306.

4. Pasricha G, Sharma S, Garg P, Aggarwal RK (2003) Use of 18S rRNA gene-based PCR assay for diagnosis of Acanthamoeba keratitis in non-contact lens wearers in India. J Clin Microbiol 41(7): 3206-3211.

5. Bharathi JM, Srinivasan M, Ramakrishnan R, Meenakshi R, Padmavathy, S, et al. (2007) A study of the spectrum of Acanthamoeba keratitis: a three-year study at a tertiary eye care referral center in South India. Indian J Ophthalmol 55(1): 37-42.

6. Dart JK, Saw VP, Kilvington S (2009) Acanthamoeba keratitis: diagnosis and treatment update 2009. Am J Ophthalmol 148(4): 487-499.

7. Shirwadkar CG, Samant R, Sankhe M, Ramesh D, Shigeo Y, et al. (2006) Acanthamoeba encephalitis in patient with systemic lupus, India. Emerg Infect Dis 12(6): 984-986.

8. Harwood CR, Rich GE, McAleer R, Cherian G (1988) Isolation of Acanthamoeba from a cerebral abscess. Med J Aust 148(1): 47-49.

9. Ringsted J, Jager BV, Suk D, Visvesvara GS (1976) Probable Acanthamoeba meningoencephalitis in a Korean child. Am J Clin Pathol 66(4): 723-730.

10. Khan NA (2008) Acanthamoeba and the blood-brain barrier: the breakthrough. J Med Microbiol 57(9): 1051-1057.

11. Marciano-Cabral F, Cabral G (2003) Acanthamoeba spp. as agents of disease in humans. Clin Microbiol Rev 16(2): 273-307.

12. Schroeder JM, Booton GC, Hay J, Niszl IA, Seal DV, et al. (2001) Use of subgenic 18S ribosomal DNA PCR and sequencing for genus and genotype identification of acanthamoebae from humans with keratitis and from sewage sludge. J Clin Microbiol 39(5): 19031911.

13. Year H, Zamfir O, Bourcier T, Ancelle T, Batellier L, et al. (2007) Comparison of PCR, microscopic examination and culture for the early diagnosis and characterization of Acanthamoeba isolates from ocular infections. Eur J Clin Microbiol Infect Dis 26(3): 221-224.
14. Booton GC, Kelly DJ, Chu YW, Seal DV, Houang E, et al. (2002) 18S ribosomal DNA typing and tracking of Acanthamoeba species isolates from corneal scrape specimens, contact lenses, lens cases, and home water supplies of Acanthamoeba keratitis patients in Hong Kong. J Clin Microbiol 40(5): 1621-1625.

15. Khoshzaban F, Dalimi A, Jabarvand M, Rezaeian M, Hashemian R (2004) PCR application in diagnosis of Acanthamoeba keratitis. Iran J Ophthalmol 30-36.

16. Lehmann OJ, Green SM, Morlet N, Kilvington S, Keys MF, et al. (1998) Polymerase chain reaction analysis of corneal epithelial and tear samples in the diagnosis of Acanthamoeba keratitis. Invest Ophthalmol Vis Sci 39(7): 1261-1265.

17. Vodkin MH, Howe DK, Visvesvara GS, McLaughlin GL (1992) Identification of Acanthamoeba at the generic and specific levels using the polymerase chain reaction. J Protozool 39(3): 378-385.

18. Zhao G, Sun S, Zhao J, Xie L (2010) Genotyping of Acanthamoeba isolates and clinical characteristics of patients with Acanthamoeba keratitis in China. J Med Microbiol 59(4): 462-466.

19. Booton GC, Visvesvara GS, Byers TJ, Daryl JK, Paul AF (2005) Identification and distribution of Acanthamoeba species Genotypes associated with non-keratitis infections. J Clini Microbiol 43(4): 16891693.

20. Niyyati M, Lorenzo-Morales J, Mohebali M, Rezaie S, Rahimi F, et al. (2009) Comparison of a PCR-Based Method with Culture and Direct Examination for Diagnosis of Acanthamoeba keratitis. Iranian Parasitol 4(2): 38-43.

21. Alexander CL, Coyne M, Jones B, Anijeet D (2015) Acanthamoeba keratitis: improving the Scottish diagnostic service for the rapid molecular detection of Acanthamoeba species. J Med Microbiol 64(7): 682687.

22. Manikandan $\mathrm{P}$, Bhaskar $\mathrm{M}$, Revathy $\mathrm{R}$, John RK, Narendran V, et al. (2004) Acanthamoeba keratitis - a six year epidemiological review from a tertiary care eye hospital in south India. Indian J Med Microbiol 22(4): 226-230. 
23. Radford CF, Lehmann OJ, Dart JK (1998) Acanthamoeba keratitis: multicentre survey in
England 1992-6. Br J Ophthalmol 82(12): 1387-1392. 